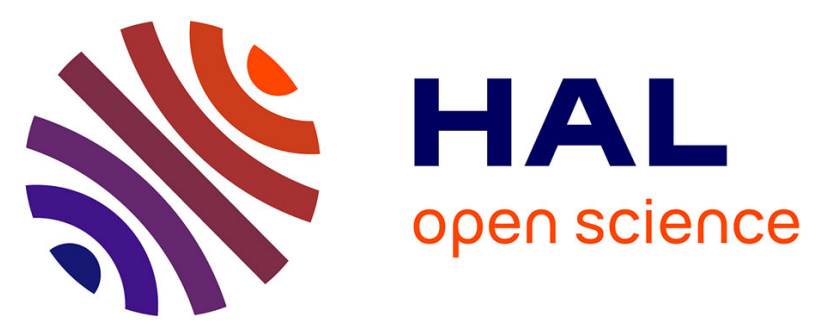

\title{
Diet, Alcohol Consumption and Cognitive Disorders in Central Africa: A Study from the EPIDEMCA Program
} Sophie Pilleron, Jean-Claude Desport, Pierre Jésus, Pascal M’Belesso, Bébène Ndamba-Bandzouzi, J-F Dartigues, Jean-Pierre Clément, Pierre-Marie Preux, Maëlenn Guerchet

\section{To cite this version:}

Sophie Pilleron, Jean-Claude Desport, Pierre Jésus, Pascal M'Belesso, Bébène Ndamba-Bandzouzi, et al.. Diet, Alcohol Consumption and Cognitive Disorders in Central Africa: A Study from the EPIDEMCA Program. Journal of Nutrition, Health \& Aging, 2015, 19 (6), pp.657-667. 10.1007/s12603015-0487-y . hal-01241244

\section{HAL Id: hal-01241244 \\ https://hal-unilim.archives-ouvertes.fr/hal-01241244}

Submitted on 3 Sep 2020

HAL is a multi-disciplinary open access archive for the deposit and dissemination of scientific research documents, whether they are published or not. The documents may come from teaching and research institutions in France or abroad, or from public or private research centers.
L'archive ouverte pluridisciplinaire HAL, est destinée au dépôt et à la diffusion de documents scientifiques de niveau recherche, publiés ou non, émanant des établissements d'enseignement et de recherche français ou étrangers, des laboratoires publics ou privés. 


\title{
DIET, ALCOHOL CONSUMPTION AND COGNITIVE DISORDERS IN CENTRAL AFRICA: A STUDY FROM THE EPIDEMCA PROGRAM
}

\author{
S. PILLERON 1,2, J.-C. DESPORT1,2,3, P. JÉSUS 1,2,3, P. MBELESSO 4 , B. NDAMBA-BANDZOUZI ${ }^{5}$, \\ J.-F. DARTIGUES 6 , J.-P. CLÉMENT 7 , P.-M. PREUX ${ }^{1,2,8}$, M. GUERCHET1,2,9 \\ FOR THE EPIDEMCA GROUP*
}

\begin{abstract}
1. INSERM, UMR 1094, Tropical Neuroepidemiology, Limoges, France; 2. Univ Limoges, UMR 1094, Tropical Neuroepidemiology, Institute of Neuroepidemiology and Tropical Neurology, CNRS FR 3503 GEIST, Limoges, France; 3. CHU Limoges, Department of Nutrition, Limoges, France; 4. Amitié Hospital, Department of Neurology, Bangui, Central African Republic; 5. CHU Brazzaville, Department of Neurology, Brazzaville, Republic of Congo; 6. INSERM U897, Bordeaux University, Bordeaux, France; 7. Hospital and University Federation of Adult and Geriatric Psychiatry, Limoges, France; 8. CHU Limoges, Centre of Epidemiology, Biostatistic, and Research Methodology, CEBIMER, Limoges, France; 9. King's College London, Centre for Global Mental Health, Institute of Psychiatry, Health Service and Population Research Department, London, UK. Corresponding author: Pr Jean-Claude Desport, Unité de nutrition, CHU Dupuytren, 2 Avenue Martin Luther King, 87042 Limoges Cedex, France, Phone: + 335550566 21, E-mail: nutrition@ unilim.fr
\end{abstract}

\begin{abstract}
Western research into dementia has focused on finding effective means of prevention, particularly through nutrition. To date, however, little is known about the relationship between diet and cognitive disorders in Africa, where the number of people with dementia is expected to increase most over the coming decades. The objective of the study was to investigate the relationship between diet and alcohol intake and cognitive disorders among elderly people in Central Africa. Between 2011 and 2012, a cross-sectional multicentre population-based study was carried out in rural and urban areas of the Central African Republic (CAR) and the Republic of Congo (ROC). Participants aged $\geq 65$ years were interviewed using the Community Screening Interview for Dementia (CSI-D). Elderly people who performed poorly (COGSCORE $\leq 24.5 / 30$ ) were clinically assessed by neurologists and underwent further psychometric testing. DSM-IV and Petersen criteria were required for a diagnosis of dementia or mild cognitive impairment (MCI), respectively. A food frequency questionnaire assessed the intakes of dairy products, fruit, vegetables, starches, legumes, oleaginous foods, meat or fish, eggs and sweet foods over the previous three days. We also collected data on alcohol intake. Sociodemographic, vascular, and psychological factors were documented. Multivariate multinomial logistic regression models were used to estimate the associations. In fully adjusted models, a lower consumption of oleaginous foods was associated with MCI $(\mathrm{OR}=3.7$ [1.4-9.9]) and dementia $(\mathrm{OR}=2.8$ [1.0-7.7] $)$ in a rural area of CAR. Alcohol consumption was associated with reduced probability of dementia in $\mathrm{CAR}(\mathrm{OR}=0.3$ [0.1-0.8]). In $\mathrm{ROC}$, food groups and alcohol intake were not associated with MCI or dementia. In conclusion, our study provides new data about the association between diet and cognitive disorders in Africa. Further studies should investigate the relationship between diet and cognitive disorders at the level of specific foods rather than food groups.
\end{abstract}

Key words: Dementia, mild cognitive impairment, diet, alcohol consumption, Central Africa.

\begin{abstract}
Abbreviations: ANR: Agence nationale de la recherche; CAR: Central African Republic; CI: Confidence Interval; CN: Cognitively normal; CSI-D: Community Screening Interview for Dementia; DSM-IV: Diagnostic and Statistical Manual; EDAC: Etude des démences en Afrique Centrale (Study of dementia in Central Africa); EPIDEMCA: Epidemiology of Dementia in Central Africa; MCI: Mild Cognitive Impairment; OR: Odds ratio; RGPH: Recensement général de la population et de l'habitat; ROC: Republic of Congo; UA: Unit of alcohol.
\end{abstract}

\section{Introduction}

Dementia is growing in prevalence worldwide. The number of cases was estimated at 44.4 million in 2013 and it is expected to reach 135.5 million by 2050 (1). The African continent is no less affected than elsewhere. In 2013, there were an estimated 2.78 million cases, rising to an expected 12.35 million by 2050 , i.e. an increase of $344 \%$ (1). Although some studies have suggested that dementia is less prevalent in Africa than in Western countries (2), suggesting that environmental factors may play a role, others have found comparable figures, particularly in urban areas (3). Data on the prevalence of mild cognitive impairment (MCI) in Africa are very scarce as only one study provides figures, for South Africa. Ramlall et al. reported a prevalence of $27.1 \%$ among participants aged 60 and over and living in residential homes for elderly people administered by a non-governmental organization (4). Little work on MCI and dementia has so far been conducted in this part of the world, despite the fact that dementia is likely to represent a heavy burden for these countries in very few decades.

In the absence of curative treatment, Western research has focused on finding ways to prevent or delay dementia, particularly through nutrition. Nutritional factors identified as potentially protective include: antioxidants, found mainly in fruits and vegetables (vitamins $\mathrm{E}, \mathrm{C}, \beta$-carotene and flavonoids); mono-unsaturated fatty acids, mainly found in vegetable oils; and poly-unsaturated fatty acids n-3 mostly found in fish $(5,6)$. Moderate alcohol consumption could also protect individuals against the risk of dementia (7). In contrast, high intakes of saturated fatty acids and polyunsaturated fatty acids $n-6$ could be risk factors (8).

African countries are experiencing a nutritional transition, 
particularly in urban areas where diets are becoming more western and therefore richer in sugars and animal products, particularly saturated fats. Such changes are often associated with reduced physical activity, thereby increasing the risk and prevalence of obesity and other chronic diseases such as diabetes, hypertension and cardiovascular disorders (9). As these conditions are risk factors for cognitive disorders in elderly people (10), it is imperative that we understand the role of nutritional factors in the development of cognitive disorders in Africa.

To date, only the Epidémiologie des Démences en Afrique Centrale (EDAC) study investigated the association between diet and dementia in Africa, finding that lower consumptions of fruit and of meat/fish were associated with dementia (11). To date, no studies have investigated the association between diet and $\mathrm{MCI}$ in Africa.

The present study investigated the relationship between dietary consumption and alcohol consumption and cognitive disorders among elderly people from rural and urban areas in two Central Africa countries, namely the Central African Republic (CAR) and the Republic of Congo (ROC). The results from the EDAC study, previously conducted in the capitals of CAR and ROC, showed that the frequencies of consumption of the main food groups differed significantly between countries. We therefore postulated that the same would be true in the present investigation. This may be explained by differences in access to food related to variations in socioeconomic profiles and food availability. This study is part of the Epidemiology of Dementia in Central Africa (EPIDEMCA) program, the main objectives of which were to estimate the prevalences of dementia and cognitive disorders in elderly people from rural and urban areas of Central Africa (ROC and CAR) and to evaluate associated factors.

\section{Method}

\section{Study Design}

The EPIDEMCA survey was a multicenter communitybased study conducted in rural and urban areas in CAR and ROC between November 2011 and December 2012 using a cross-sectional two-phase design.

\section{Study areas}

Urban areas studied were the capitals of the two countries, namely Bangui in CAR and Brazzaville in ROC. The population of Bangui was estimated at 622,771 inhabitants in 2003 (RGPH 2003), with 1.4\% of people aged 65 and above. Brazzaville counted 1,373,382 inhabitants in 2007, representing $37.1 \%$ of the total ROC population. People aged 65 and above accounted for 2.3\% of Brazzaville's population (RGPH 2007). Rural areas in each country were selected for security and feasibility reasons. In CAR, Nola and villages within a $10-\mathrm{km}$ radius in the prefecture of Sangha-Mbaéré at the southwestern tip of the country were selected. In ROC, Gamboma located in the Gamboma district, Plateaux Region, was selected.

\section{Sample}

\section{Inclusion criteria}

Subjects aged 65 years and above and currently living in the study area were included unless they declined to participate or presented severe comorbidities precluding cognitive testing particularly deaf-mute people and bedridden people too frail to be interviewed.

\section{Sample size and selection}

The primary objective of the EPIDEMCA program being to estimate dementia prevalence, we aimed to include a minimum of 456 participants from each site in order to detect a prevalence of 5\% with a precision of $2 \%$ (EpiInfo 6.04, Epiconcept). We rounded up to 500 subjects. In urban areas, the sample was selected using a random sampling proportional to the main city subdivision size. In rural areas, exhaustive sampling using a door-to-door approach was preferred due to logistic and financial constraints.

\section{Ethics}

Town halls were informed of the study and neighborhood leaders were visited prior to starting the survey in order to increase awareness. Moreover, information was broadcast on the local radio. Participants were not remunerated, but a few basic drugs (such as analgesics and vermifuges) were distributed after physical examination if necessary, and a more thorough medical examination by a doctor could be proposed.

Approvals were obtained from the Ministry of Public Health in CAR, the CERSSA (Comité d'Ethique de la Recherche en Sciences de Santé) in ROC and Comité de Protection des Personnes du Sud-Ouest et d'Outre-Mer 4 in France. All participants and/or their families gave informed consent before being included in the study.

\section{Assessment of cognitive disorders}

During the first phase, cognitive testing was performed using the Community Screening Interview for Dementia (CSI-D) (12) adapted, back-translated and pretested in the local languages (Sango in CAR, Lari, Lingala, and Kituba in ROC). A relative of each elderly person included was interviewed at the same time using the CSI-D informant section to assess daily activities and any personality changes. Every subject with a poor performance in the CSI-D cognitive tests (COGSCORE $\leq 24.5$ ) was recorded as having suspected cognitive impairment and invited for further clinical assessment.

The second phase took place at the hospital 3 to 14 weeks later. Further psychometric tests were conducted, including the Free and Cued Selective Reminding Test (13), Zazzo's cancellation task (14) and Isaac's Set Test of verbal fluency (15). Neurologists performed specialist examinations during which histories of stroke and depressive disorders were sought. 
Orientation skills and daily activities were also investigated in order to evaluate the level of dependence.

The diagnosis of dementia was made according to DSMIV criteria (16) based on, firstly, the development of multiple cognitive deficits manifested by memory impairment plus one of four cognitive disturbances (aphasia, apraxia, agnosia, disordered executive functioning); secondly, these cognitive deficits were required to cause significant impairment in social or occupational functioning (15). The diagnosis of MCI was based on Petersen criteria (17) that include memory complaint, normal activities of daily living, normal general cognitive function, abnormal memory for age and no dementia (16). An experienced neurologist reviewed all medical records and test performances in order to reach a consensus on uncertain cases.

\section{Dietary assessment}

During the first phase, a 8-item food frequency questionnaire (FFQ) was administered by interviewers to each individual to assess the frequency of intakes of broad categories of food over the previous three days: dairy products (milk, cheese, yogurt...), fruits, vegetables (tomatoes, carrots, gumbo, avocado, eggplant...), starches (corn, millet, sorghum, rice, wheat, sweet potato, yam, plantain, potato...), legumes (dry bean, chick pea, lentil...), oleaginous foods (peanut, sesame...), meats or fishes, eggs and sweet foods (soda, sugar, honey...). This FFQ was previously used in the EDAC study (11) but also in another study about nutrition and epilepsy (18). In cases where the elderly person was unable to respond, an informant - generally a close relative or someone living with the subject answered on his or her behalf.

\section{Alcohol consumption assessment}

Alcohol consumption was assessed during the first phase using the following question: "How many doses of alcohol do you drink in a normal week?" We considered that one dose of beer was $33 \mathrm{cl}$; liquor $25 \mathrm{ml}$ and local drinks $500 \mathrm{ml}$. From these data, we generated the number of units of alcohol (UA) consumed in a normal week $(1 \mathrm{UA}=10 \mathrm{~g})$.

\section{Other data collected}

All covariates were collected during the first phase. Sociodemographic data included age, gender, marital status, formal education and area (urban; rural). Age was ascertained from official documents, or using historical events $(19,20)$ or from an informant if previous methods were unsuccessful. Vascular covariates included smoking status (current nonsmoker [including former smoker]; current smoker), body mass index (BMI) (in three categories: $<18.50 \mathrm{~kg} / \mathrm{m}^{2}$ for undernutrition; $18.50-24.99 \mathrm{~kg} / \mathrm{m}^{2}$ for normal nutritional status; $\geq 25.00 \mathrm{~kg} / \mathrm{m}^{2}$ for overweight) (21), hypertension (defined as having systolic blood pressure $\geq 140 \mathrm{mmHg}$ and/ or diastolic blood pressure $\geq 90 \mathrm{mmHg}$ or currently taking antihypertensive drugs) (22), diabetes (defined as currently taking antidiabetic drugs or having glycaemia greater than
$126 \mathrm{mg} / \mathrm{dl}$ for more than 2 hours or greater than $200 \mathrm{mg} / \mathrm{dl}$ in non-fasting participants), history of stroke, physical activity (defined as having walked or cycled at least $150 \mathrm{~min}$ in the previous week) (23). Depressive and anxiety symptoms were assessed with the Geriatric Mental State version B3 (24). Dependent personality disorder (DPD) was assessed using the DPD domain of the Personality Diagnostic Questionnaire - 4+ (25). The DPD domain contains eight true-false items corresponding to the DSM-IV diagnostic criteria. A person was considered as having DPD if the "True" option was selected for at least five items.

\section{Data management and analysis}

All data collected were computerized directly in the field using an interface especially created with Epidata version 3.1 (EpiData Association, Odense, Denmark). Cognitive disorders used as categorical variables were our dependent variable consisting of three categories: cognitively normal $(\mathrm{CN}), \mathrm{MCI}$ and dementia.

From the intake over the previous three days, the mean number of intakes per day was calculated for each food group. We then categorized the variable into two $(<1$ per day; 1 or more per day) or three classes ( $<1$ per day; $1-2$ per day; 2 or more per day) depending on the distribution of the responses.

For descriptive purposes, we divided the quantity of alcohol into three categories: abstainers ( 0 UA consumed in a normal week); light consumers (>0-6 UA consumed in a normal week) and moderate-to-heavy consumers ( 7 or more UA consumed in a normal week). For multivariate analyses, we dichotomized the quantity of alcohol consumed to create the variable "alcohol consumer" (yes/no) as the number of cases was not sufficient to run fully adjusted models.

All covariates were used as categorical variables, except for age, which was used as a continuous variable because the linearity hypothesis could not be rejected.

As we postulated that dietary habits are different between countries, we performed separate analyses for each country. Means with their standard deviations were used as summary statistics for age. Percentages were calculated for all categorical variables. Univariate analyses were carried out between our dependent variable and our independent variables on one hand, and all potential covariates on the other using $\mathrm{Chi}^{2}$ test, Fisher exact test or t-test when appropriate. Unadjusted analysis using multinomial logistic regression models was used to test the relationship of cognitive disorders with each food group and alcohol intake. Each independent variable and covariate associated with cognitive disorders at $\mathrm{p}<0.20$ in univariate analysis was entered into a multivariate multinomial logistic regression model. A backward stepwise selection procedure was used to retain covariates with $\mathrm{p}<0.10$, and all sociodemographic variables were forced into models. In the final models, we tested for interaction between each food group that remained in the model and gender on one hand and living area (rural/urban) on the other. The level of significance was 
Table 1

Comparison of main characteristics between excluded and included participants, EPIDEMCA, 2011-2012

\begin{tabular}{|c|c|c|c|c|c|c|c|}
\hline & \multicolumn{3}{|c|}{ Excluded (n=229) } & \multicolumn{3}{|c|}{ Included $(\mathrm{n}=1772)$} & \multirow[b]{2}{*}{$\mathbf{p}$} \\
\hline & $\mathbf{n}$ & $\%$ or mean, sd & md & $\mathbf{n}$ & $\%$ or mean, sd & md & \\
\hline Area, $\%$ & & & 0 & & & 0 & $<0.001$ \\
\hline Nola & 65 & 28.38 & & 408 & 23.02 & & \\
\hline Bangui & 48 & 20.96 & & 452 & 25.51 & & \\
\hline Gamboma & 95 & 41.48 & & 433 & 24.44 & & \\
\hline Brazzaville & 21 & 9.17 & & 479 & 27.03 & & \\
\hline Age (mean, SD) & 229 & $73.10,6.67$ & 0 & 1772 & $74.75,6.69$ & 0 & $<0.001$ \\
\hline Female, $\%$ & 182 & 79.48 & 0 & 1047 & 59.09 & 0 & $<0.001$ \\
\hline In couple, $\%$ & 44 & 19.21 & 0 & 687 & 38.88 & 5 & $<0.001$ \\
\hline No formal education, $\%$ & 200 & 87.34 & 0 & 1173 & 66.38 & 5 & $<0.001$ \\
\hline History of stroke, $\%$ & 14 & 6.11 & 0 & 118 & 6.68 & 5 & 0.746 \\
\hline BMI, \% & & & 22 & & & 91 & $<0.001$ \\
\hline$<18.5 \mathrm{~kg} / \mathrm{m}^{2}$ & 88 & 42.51 & & 556 & 33.08 & & \\
\hline $18.5-24.9 \mathrm{~kg} / \mathrm{m}^{2}$ & 107 & 51.69 & & 832 & 49.49 & & \\
\hline$\geq 25.0 \mathrm{~kg} / \mathrm{m}^{2}$ & 12 & 5.80 & & 293 & 17.43 & & \\
\hline Hypertension, \% & 139 & 61.23 & 2 & 1075 & 61.01 & 10 & 0.948 \\
\hline Diabetes, $\%$ & 16 & 7.08 & 3 & 142 & 8.21 & 42 & 0.558 \\
\hline Current smoker, $\%$ & 58 & 25.66 & 3 & 382 & 21.66 & 8 & 0.172 \\
\hline Physical activity, \% & 50 & 22.03 & 2 & 504 & 28.70 & 16 & 0.035 \\
\hline Depressive symptoms, $\%$ & 113 & 49.34 & 0 & 649 & 36.63 & 0 & $<0.001$ \\
\hline Anxiety symptoms, $\%$ & 22 & 9.61 & 0 & 133 & 7.51 & 0 & 0.263 \\
\hline Dependent personality disorder, $\%$ & 45 & 20.55 & 10 & 255 & 14.53 & 17 & 0.019 \\
\hline Dairy products, $\%$ & & & 3 & & & 9 & $<0.001$ \\
\hline$<1 / \mathrm{d}$ & 212 & 93.81 & & 1488 & 84.40 & & \\
\hline $1+/ d$ & 14 & 6.19 & & 275 & 15.60 & & \\
\hline Fruits, $\%$ & & & 3 & & & 12 & 0.037 \\
\hline$<1 / \mathrm{d}$ & 203 & 89.82 & & 1489 & 84.60 & & \\
\hline $1+/ d$ & 23 & 10.18 & & 271 & 15.40 & & \\
\hline Vegetables, $\%$ & & & 3 & & & 10 & 0.051 \\
\hline$<1 / \mathrm{d}$ & 114 & 50.44 & & 744 & 42.22 & & \\
\hline $1-2 / \mathrm{d}$ & 74 & 32.74 & & 638 & 36.21 & & \\
\hline $2+/ d$ & 38 & 16.81 & & 380 & 21.57 & & \\
\hline Starches, $\%$ & & & 3 & & & 11 & 0.024 \\
\hline$<1 / \mathrm{d}$ & 52 & 23.01 & & 279 & 15.84 & & \\
\hline $1-2 / \mathrm{d}$ & 86 & 38.05 & & 745 & 42.31 & & \\
\hline $2+/ d$ & 88 & 38.94 & & 737 & 41.85 & & \\
\hline Legumes, $\%$ & & & 3 & & & 11 & 0.070 \\
\hline$<1 / \mathrm{d}$ & 57 & 25.22 & & 353 & 20.05 & & \\
\hline $1+/ d$ & 169 & 74.78 & & 1408 & 79.95 & & \\
\hline Oleaginous food, $\%$ & & & 3 & & & 16 & 0.657 \\
\hline$<1 / \mathrm{d}$ & 167 & 73.89 & & 1273 & 72.49 & & \\
\hline $1+/ d$ & 59 & 26.11 & & 483 & 27.51 & & \\
\hline
\end{tabular}


Sweet food, \%

$\begin{array}{lcc}<1 / \mathrm{d} & 185 & 81.86 \\ 1+/ \mathrm{d} & 41 & 18.14 \\ \text { Meat, fish, egg, \% } & & \\ <1 / \mathrm{d} & 97 & 44.29 \\ 1-2 / \mathrm{d} & 73 & 33.33 \\ 2+/ \mathrm{d} & 49 & 22.37 \\ \text { Alcohol consumers, \% } & 40 & 17.78\end{array}$

d: day; md: Missing data; SD: Standard deviation

fixed at 0.05 for all analyses, except for interaction tests for which Bonferroni correction was used to control for overall Type I error rate over the multiple tests $\left(\alpha_{\text {Bonferroni }}<0.05 /\right.$ number of tests). The statistical analysis was carried-out using Stata version 10.1 for Windows (StataCorp, College Station, TX).

\section{Results}

During the first phase in the general population, 2113 people aged 65 and above were approached; 111 declined to participate in the survey. Of the remaining 2002 participants, 775 were invited to clinical interview and 555 actually came. At the end of the second phase, 118 had MCI, 135 had dementia and 1519 had normal cognition. We did not have neurological data for 229 subjects, who were therefore excluded from our analysis. One participant was excluded because of missing age, leaving 1772 participants for analysis. The detailed flow chart is presented in Figure 1.

Figure 1

Flow chart of the EPIDEMCA study in CAR and ROC, 2011-2012

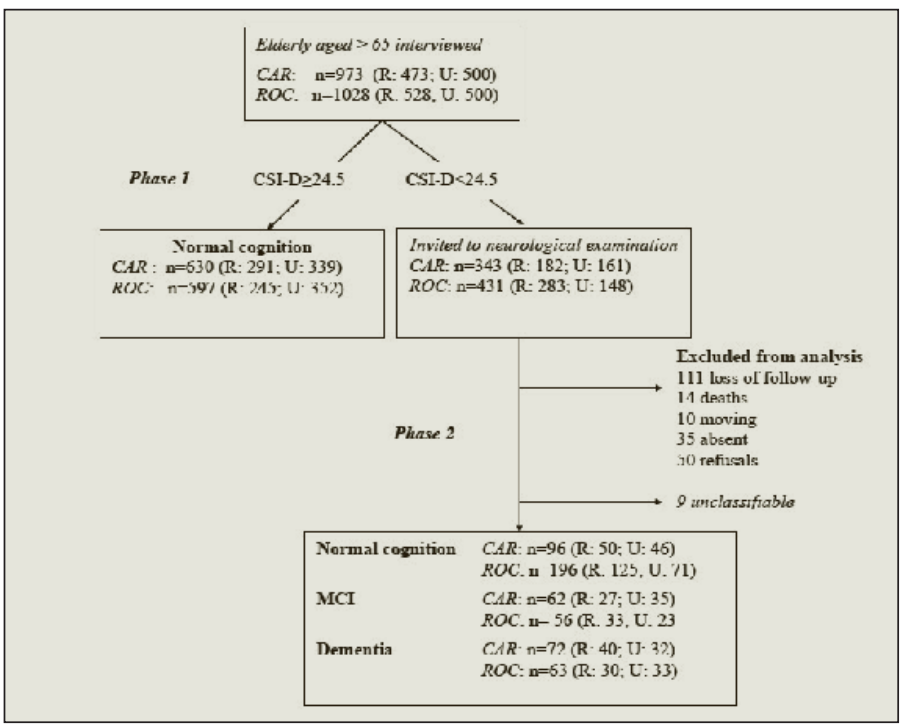

CAR: Central African Republic; CSI-D: Community Screening for Dementia; MCI: Mild Cognitive Impairment; R: Rural area; ROC: Republic of Congo; U: Urban area
11

0.002

10

$1270 \quad 72.12$

$491 \quad 27.88$

34

0.010

$589 \quad 33.89$

$698 \quad 40.16$

$451 \quad 25.95$

4

566

32.20

14

$<0.001$

Table 1 shows the characteristics of the 1772 included participants compared to the 229 excluded ones. Subjects excluded differed significantly from those included regarding residence area $(p<0.001)$. They were younger $(p<0.001)$, mainly female $(\mathrm{p}<0.001)$, less likely to be in a couple $(p<0.001)$, less educated $(p<0.001)$, less corpulent $(p<0.001)$, and more depressed $(\mathrm{p}<0.001)$. Regarding their dietary consumption, participants excluded were less likely to consume dairy products $(\mathrm{p}<0.001)$, fruits $(\mathrm{p}=0.037)$, starches $(\mathrm{p}=0.024)$, meat/fish/egg $(\mathrm{p}=0.010)$, sweet foods $(\mathrm{p}=0.002)$ and alcohol $(\mathrm{p}<0.001)$.

Table 2 presents the general characteristics of the 1772 EPIDEMCA participants included according to their country of residence. CAR participants were younger than ROC ones $(p<0.001)$. They were less hypertensive $(p<0.001)$, diabetic $(\mathrm{p}<0.001)$, depressed $(\mathrm{p}<0.001)$, and anxious $(\mathrm{p}<0.001)$. However, they were more likely to be smokers $(p<0.001)$, to be physically active $(\mathrm{p}<0.001)$, and to have a dependent personality disorder. Our postulate is confirmed by our results. Indeed, CAR participants were more likely than ROC ones to eat fruits $(p<0.001)$, vegetables $(p<0.001)$, oleaginous foods $(\mathrm{p}<0.001)$, and sweet foods $(\mathrm{p}<0.001)$. However, the latter were more likely to eat starches $(\mathrm{p}<0.001)$ and meat/fish/egg $(\mathrm{p}<0.001)$. In both countries, most participants did not drink alcohol. Among those who did, most were light consumers. In CAR, among alcohol consumers, the median number of UA consumed in a typical week was $2.0 \pm 3.6 \mathrm{UA}$ with a maximum of $46 \mathrm{UA}$. In ROC, the median was $3.5 \pm 9.1 \mathrm{UA}$ with a maximum of $191.5 \mathrm{UA}$. The two distributions did not differ significantly $(\mathrm{p}=0.264)$.

Table 3 and Table 4 display the results of univariate and multivariate analyses of the association between cognitive disorders and food groups and alcohol consumption in CAR and ROC, respectively. In CAR, a significant interaction was found between oleaginous food and area (urban/rural) in multivariate analysis $(\mathrm{p}=0.004)$. This interaction remained significant even after application of the threshold corrected according to Bonferroni procedure $\left(\alpha_{\text {Bonferroni }}<0.05 / 12\right.$ tests $=0.004)$. Lower intake of oleaginous food was associated with a higher probability of MCI and dementia in rural areas while no association was observed in urban areas (Table 3). Alcohol intake was associated with a reduced probability of dementia. In ROC, in multivariate analysis, food groups were 
Table 2

Comparison of characteristics of included participants between CAR and ROC, EPIDEMCA, 2011-2012

\begin{tabular}{|c|c|c|c|c|c|c|c|}
\hline & & CAR $(n=860)$ & & & $\operatorname{ROC}(n=912)$ & & \\
\hline & $\mathbf{n}$ & $\%$ or mean, sd & md & $\mathbf{n}$ & $\%$ or mean, sd & md & $\mathbf{p}$ \\
\hline Age (mean, SD) & 841 & $72.41,6.41$ & 0 & 931 & $73.74,6.84$ & 0 & $<0.001$ \\
\hline Living in rural area, $\%$ & 408 & 47.44 & 0 & 433 & 47.48 & 0 & 0.988 \\
\hline Female, $\%$ & 513 & 59.65 & 0 & 534 & 58.55 & 0 & 0.638 \\
\hline In couple, $\%$ & 318 & 37.06 & 2 & 369 & 40.59 & 3 & 0.128 \\
\hline No formal education, $\%$ & 570 & 66.43 & 2 & 603 & 66.34 & 3 & 0.966 \\
\hline History of stroke, $\%$ & 72 & 8.39 & 2 & 46 & 5.06 & 3 & 0.005 \\
\hline Hypertension, $\%$ & 458 & 53.50 & 4 & 617 & 68.10 & 6 & $<0.001$ \\
\hline Diabetes, $\%$ & 39 & 4.67 & 24 & 103 & 11.52 & 18 & $<0.001$ \\
\hline Current smokers, $\%$ & 266 & 31.04 & 3 & 116 & 12.79 & 5 & $<0.001$ \\
\hline Physical activity, \% & 337 & 39.65 & 10 & 167 & 18.43 & 6 & $<0.001$ \\
\hline Depressive symptoms, $\%$ & 274 & 31.86 & 0 & 375 & 41.12 & 0 & $<0.001$ \\
\hline Anxiety symptoms, $\%$ & 31 & 3.60 & 0 & 102 & 11.18 & 0 & $<0.001$ \\
\hline Dependent personality disorders, $\%$ & 149 & 17.51 & 9 & 106 & 11.73 & 8 & 0.001 \\
\hline Dairy products, $\%$ & & & 6 & & & 3 & 0.141 \\
\hline$<1 / \mathrm{d}$ & 732 & 85.71 & & 756 & 83.17 & & \\
\hline $1+/ \mathrm{d}$ & 122 & 14.29 & & 153 & 16.83 & & \\
\hline Fruits, $\%$ & & & 7 & & & 5 & $<0.001$ \\
\hline$<1 / \mathrm{d}$ & 659 & 77.26 & & 830 & 91.51 & & \\
\hline $1+/ \mathrm{d}$ & 194 & 22.74 & & 77 & 8.49 & & \\
\hline Vegetables, $\%$ & & & 7 & & & 3 & $<0.001$ \\
\hline$<1 / \mathrm{d}$ & 252 & 29.54 & & 492 & 54.13 & & \\
\hline $1-2 / d$ & 364 & 42.67 & & 274 & 30.14 & & \\
\hline $2+/ d$ & 237 & 27.78 & & 143 & 15.73 & & \\
\hline Starches, $\%$ & & & 7 & & & 4 & $<0.001$ \\
\hline$<1 / \mathrm{d}$ & 194 & 22.74 & & 85 & 9.36 & & \\
\hline $1-2 / \mathrm{d}$ & 342 & 40.09 & & 403 & 44.38 & & \\
\hline $2+/ d$ & 317 & 37.16 & & 420 & 46.26 & & \\
\hline Legumes, $\%$ & & & 8 & & & 3 & $<0.001$ \\
\hline$<1 / \mathrm{d}$ & 253 & 29.69 & & 100 & 11.00 & & \\
\hline $1+/ d$ & 599 & 70.31 & & 809 & 89.00 & & \\
\hline Oleaginous food, $\%$ & & & 11 & & & 5 & $<0.001$ \\
\hline$<1 / \mathrm{d}$ & 457 & 53.83 & & 816 & 89.97 & & \\
\hline $1+/ \mathrm{d}$ & 392 & 46.17 & & 91 & 10.03 & & \\
\hline Sweet food, \% & & & 7 & & & 4 & $<0.001$ \\
\hline$<1 / \mathrm{d}$ & 487 & 57.09 & & 783 & 86.23 & & \\
\hline $1+/ \mathrm{d}$ & 366 & 42.91 & & 125 & 13.77 & & \\
\hline Meat, fish, egg, $\%$ & & & 8 & & & 26 & $<0.001$ \\
\hline$<1 / \mathrm{d}$ & 463 & 54.34 & & 126 & 14.22 & & \\
\hline $1-2 / \mathrm{d}$ & 255 & 29.93 & & 443 & 50.00 & & \\
\hline $2+/ d$ & 134 & 15.73 & & 317 & 35.78 & & \\
\hline
\end{tabular}


Alcohol consumers, $\%$

\begin{tabular}{lcc} 
Abstainers & 577 & 67.80 \\
Light & 240 & 28.20 \\
Moderate-to-heavy & 34 & 4.00 \\
\hline CAR: Central African Republic; d: day; md: Missing data; ROC: Republic of Co \\
\multicolumn{4}{l}{ ssociated with neither MCI nor dementia (Table 4). The same } \\
was observed for alcohol intake.
\end{tabular}

\section{Discussion}

The present study aimed to study the association between dietary intake, including alcohol, and cognitive disorders, namely MCI and dementia, in a sample of elderly people from rural and urban areas of Central Africa. To our knowledge, it is the first population-based study to specifically investigate this relationship in Africa.

In CAR, a significant inverse association was observed between intake of oleaginous foods and MCI and dementia in the rural area, and the magnitude of the association in the urban area suggested a positive association. Oleaginous foods are the main dietary source of monounsaturated fatty acids (MUFA), which have been associated with a decreased risk of cognitive disorders (26-29). This is congruent with our result in rural areas but not in urban areas. The difference may be explained by the different types of oleaginous foods consumed between rural and urban areas. In rural CAR, the main type is groundnut oil and in urban CAR we found pumpkin seed oil, sheanut oil, and sesame oil. As we worked at the level of food groups level and not individual foods, our analysis did not distinguish between the kinds of oil consumed. The different oils vary in the fatty acids they contain. Groundnut oil is mainly composed of unsaturated fatty acid (78.2\%) including $46.2 \%$ MUFA and $32.0 \%$ polyunsaturated fatty acids (PUFA) (30). Sesame oil is similar $(72.4 \%$ unsaturated with $39.7 \%$ and $41.7 \%$ MUFA and PUFA, respectively) (30) as is pumpkin seed oil (78-79\% with 28.2-34.0\% MUFA and 43.0-53.0\% PUFA) (31). However, sheanut oil contains lower levels of unsaturated fatty acids (49.2\%) mainly represented by MUFA (44.0\%) and thus higher levels of saturated fatty acids (46.6\%) (30), which have been associated with increased risk of cognitive disorders $(26,27)$.

The analysis at food group level and not individual food level may also explain why no other food groups were associated with MCI or dementia in CAR or ROC. The EDAC study showed that people with dementia consumed less fruit and meat/fish than did controls (11). However, the objective, the sampling method and the analysis strategy were different from our study.

Seventy-five percent of our sample lived with their adult children, who usually prepared the same meal for all members of the household, meaning that only the quantity could differ. Food intake decreases with increasing severity of dementia pathology due to brain damage, psychological, behavioral and
67.81

23.59

8.60

\begin{tabular}{cc}
615 & 67.81 \\
214 & 23.59 \\
78 & 8.60 \\
\hline
\end{tabular}

sensory symptoms, social factors, oral and dental health and motor disturbances (for review, see (32)). This may partially explain the lack of association with most food groups in our study because we assessed the frequency of consumption and not the quantity.

In the literature, some food groups are reported to be protective against or risk factors for cognitive disorders. Frequent consumption of fruits and vegetables has been associated with a decreased risk of Alzheimer's disease, dementia and cognitive decline $(5,33-35)$. Fish has been associated with a reduced risk of dementia mainly due to its omega 3 fatty acid content whereas meat was associated with a higher risk in western countries as well as in low and middle income parts of the world $(5,36)$. However, few western studies analyzed the relationship between MCI and dietary consumption and most that did were specifically interested in the Mediterranean diet $(37,38)$, which is not relevant to our context.

In the present study, alcohol intake was associated with a lower probability of MCI and dementia in CAR. Most alcohol consumers had a low intake, with around $88 \%$ of respondents in CAR and $73 \%$ in ROC declaring drinking less than seven UA in a typical week. These results are consistent with several western studies $(39,40)$ even if some others are contradictory $(7,41)$. Moderate intake of alcohol would be associated with reduced risk of dementia through the reduction of vascular risk factors (for review, see (39)).

Some limitations are described above. In addition, because our study is cross-sectional in design, it tells us nothing about the temporality of the associations observed. The low numbers of prevalent cases of MCI and dementia by country could affect the precision of estimates and lead to non-significant associations. This also led us to group together meats, fishes and eggs, and thereby obscure possible associations. Some studies have suggested that ApoE genotype could modify the relationship between some foods and alcohol consumption and cognitive disorders $(5,42)$ but the ApoE genotype was not available here. We cannot exclude the existence of recall bias but we believe it is limited as in our study areas meals are prepared for the whole household and generally by children or grandchildren who were also our informants. Moreover, unlike in western countries, meals are very similar from one day to another. Finally, because we worked at food group level we did not expect details of all foods consumed over the previous three days. 


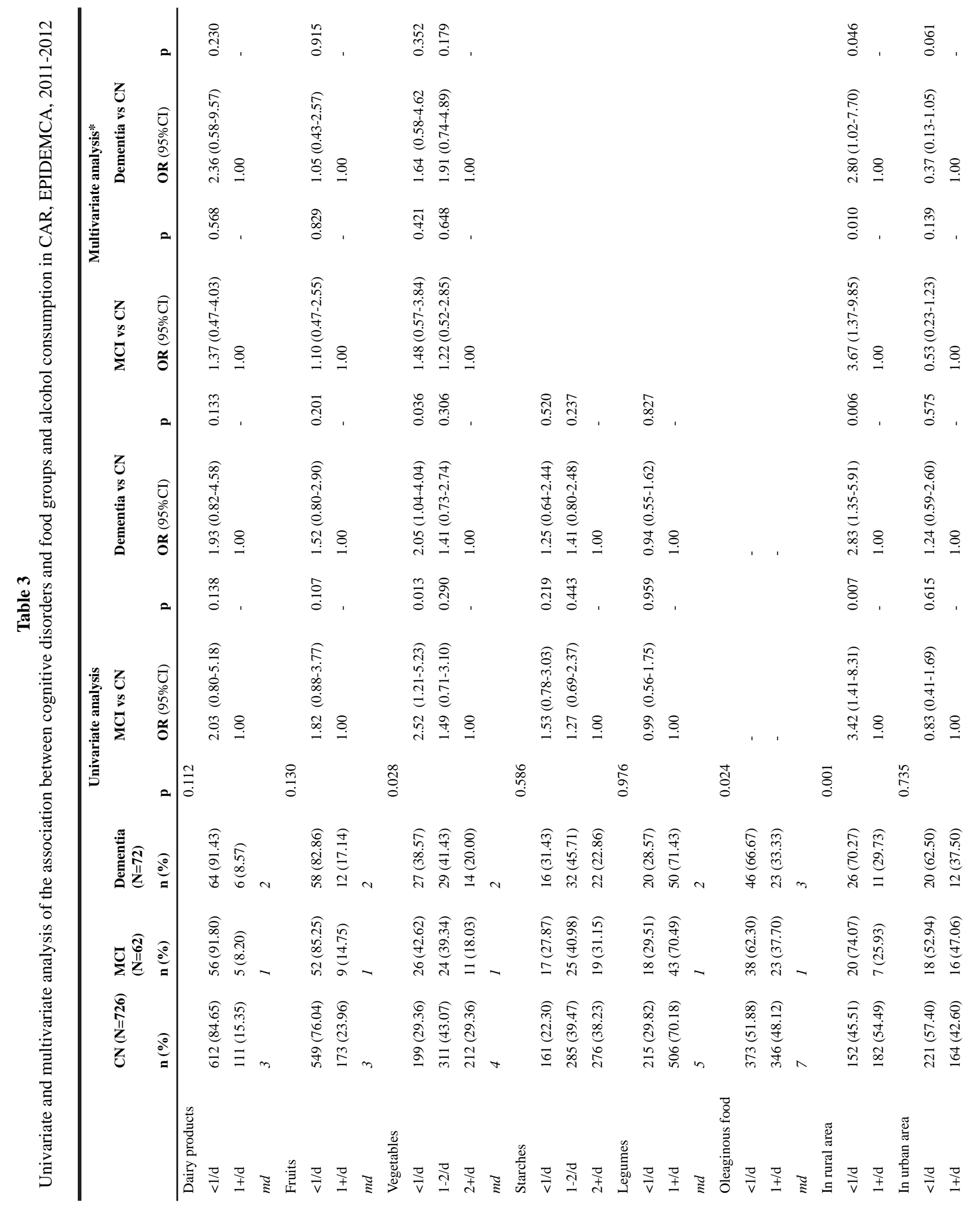




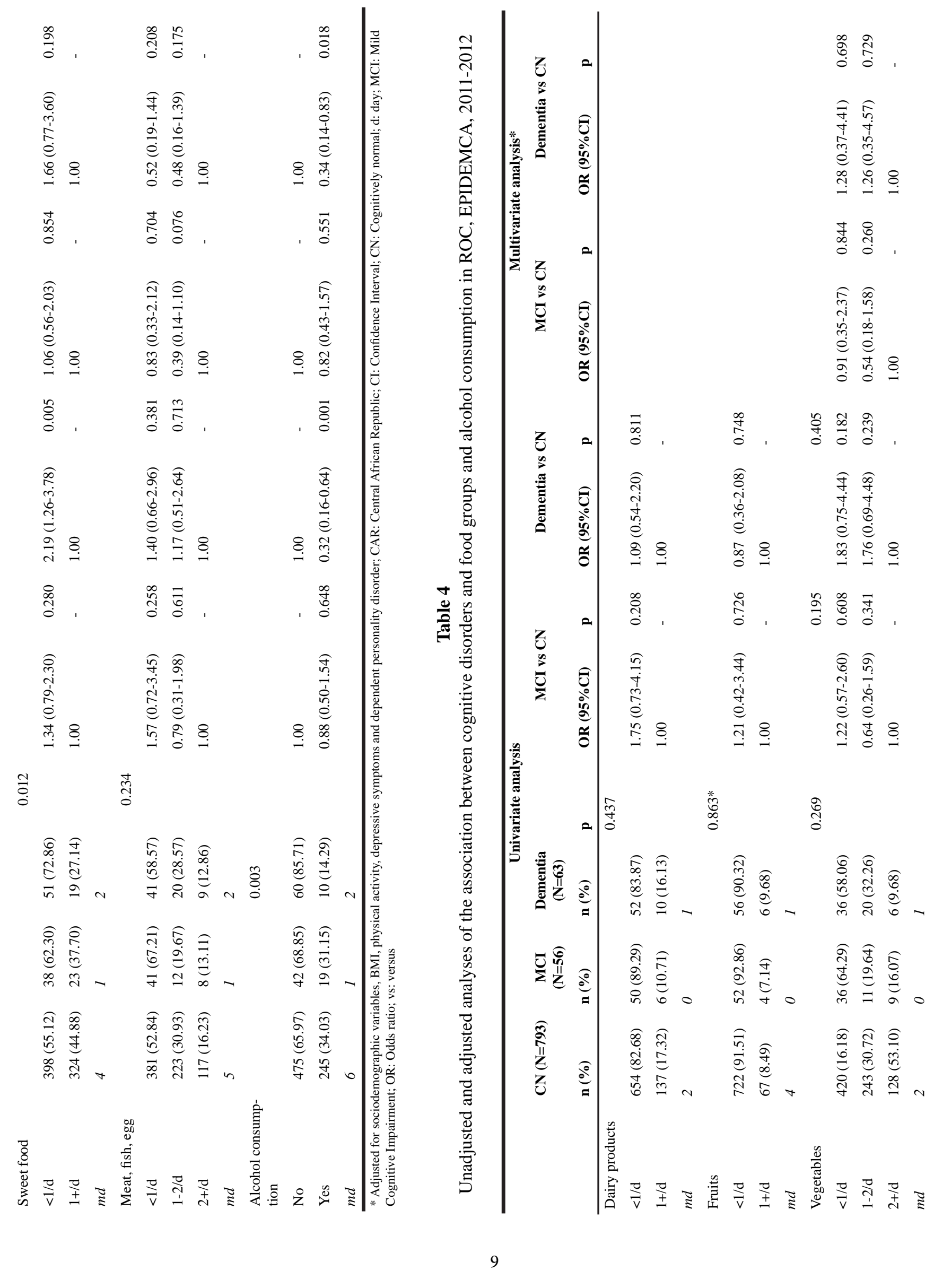




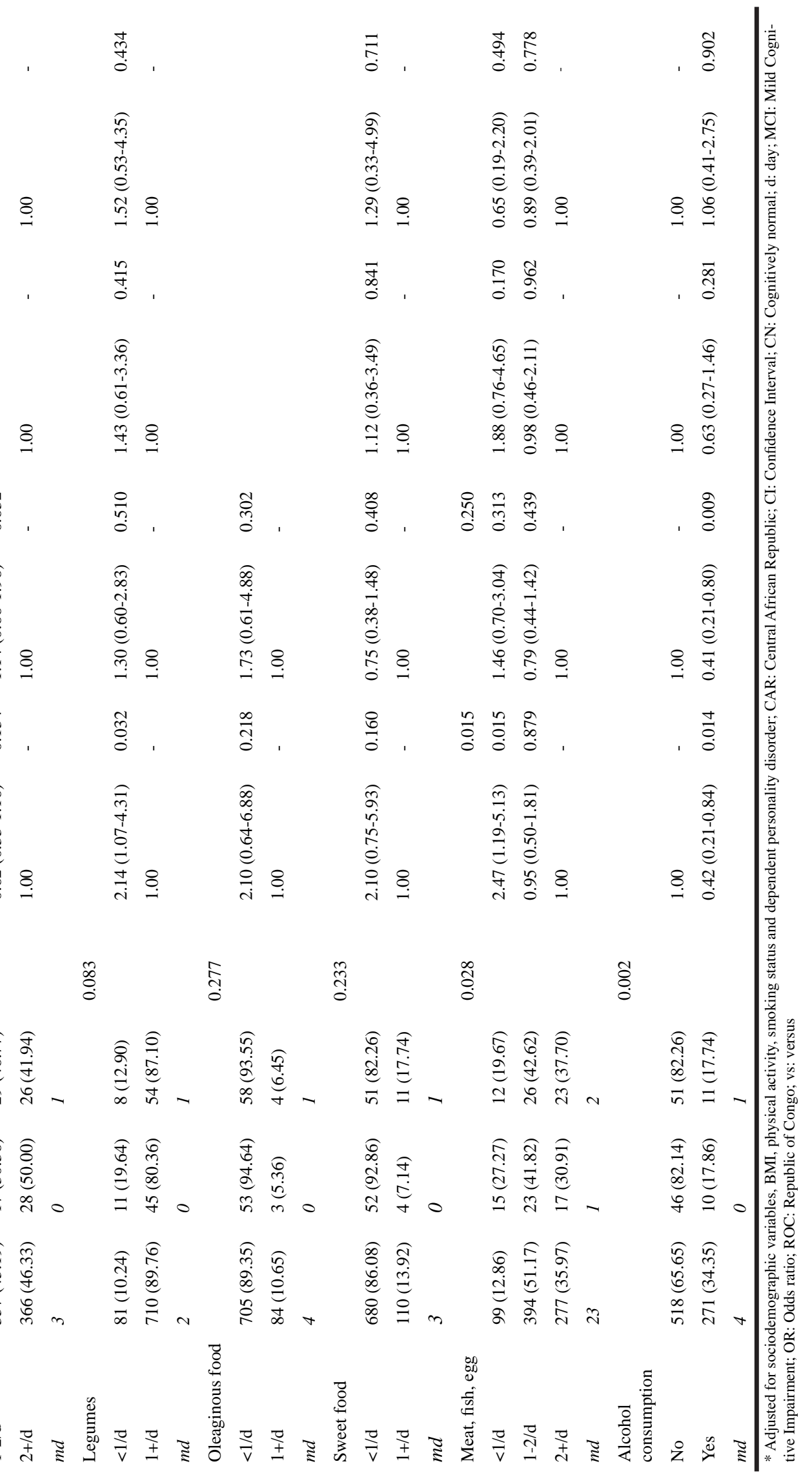


In conclusion, this study provides a first insight into the association between diet and cognitive disorders in Africa. Future studies should be conducted in larger samples to further investigate the role of diet, at food level, in cognitive disorders in this context.

EPIDEMCA group: Maëlenn Guerchet, Bébène Ndamba-Bandzouzi, Pascal Mbelesso, Sophie Pilleron, Iléana Désormais, Philippe Lacroix, Victor Aboyans, Jean-Claude Desport, Pierre Jésus, Achille E. Tchalla, Benoît Marin, Jean-Pierre Clément, Jean-Charles Lambert, Jean-François Dartigues and Pierre-Marie Preux.

Acknowledgments: The authors would like to thank the participants in the EPIDEMCA study as well as all the researchers and nurses involved in this project for their assistance. Thanks also to the town halls, mayors, and chiefs of districts for their collaboration, the Universities of Bangui (Central African Republic) and Marien Ngouabi in Brazzaville (Republic of Congo), the Health ministries of the Central African Republic and the Republic of Congo, for their support. We would like to thank Dr P. Nubukpo for proofreading this article and his valuable advice. The authors' responsibilities were as follows-All authors worked collectively to design the EPIDEMCA protocol; SP, MG, PM, BNB, JFD participated in data collection in the field; SP analyzed data and drafted the paper; other authors reviewed the manuscript, provided further contributions an suggestions; SP had primary responsibility for the final content. All authors read and approved the final manuscript. The authors reported no conflicts of interest. The sources of funding had no role in the design, implementation, analysis, or interpretation of the data.

Source of support: The French National Research Agency (ANR) funded this study through the ANR-09-MNPS-009-01 grant. The University of Limoges, Doctoral School 523 of Limoges University, the Limousin Regional Council and the French Ministry of Higher Education and Research funded the doctoral position of SP.

Conflict of interest: No conflicts of interest to declare.

\section{References}

1. Prince M, Guerchet M, Prina M. Policy Brief for Heads of Government: The Globa Impact of Dementia 2013-2050. London: Alzheimer's Disease International; 2013.

2. Hendrie HC, Osuntokun BO, Hall KS, Ogunniyi AO, Hui SL, Unverzagt FW, Gureje O, Rodenberg CA, Baiyewu O, Musick BS. Prevalence of Alzheimer's disease and dementia in two communities: Nigerian Africans and African Americans. Am J Psychiatry 1995;152:1485-92.

3. Guerchet M, M'belesso P, Mouanga AM, Bandzouzi B, Tabo A, Houinato DS, Paraïso MN, Cowppli-Bony P, Nubukpo P, Aboyans V, et al. Prevalence of dementia in elderly living in two cities of Central Africa: the EDAC survey. Dement Geriatr Cogn Disord 2010;30:261-8.

4. Ramlall S, Chipps J, Pillay BJ, Bhigjee AL. Mild cognitive impairment and dementia in a heterogeneous elderly population: prevalence and risk profile. Afr J Psychiatry 2013;16:456-465.

5. Barberger-Gateau P, Raffaitin C, Letenneur L, Berr C, Tzourio C, Dartigues JF, Alpérovitch A. Dietary patterns and risk of dementia: the Three-City cohort study. Neurology 2007;69:1921-30.

6. Morris MC. Nutritional determinants of cognitive aging and dementia. Proc Nutr Soc 2012;71:1-13.

7. Neafsey EJ, Collins MA. Moderate alcohol consumption and cognitive risk. Neuropsychiatr Dis Treat 2011;7:465-84.

8. Solfrizzi V, Panza F, Frisardi V, Seripa D, Logroscino G, Imbimbo BP, Pilotto A Diet and Alzheimer's disease risk factors or prevention: the current evidence. Expert Rev Neurother 2011;11:677-708.

9. Vorster HH, Kruger A, Margetts BM. The nutrition transition in Africa: can it be steered into a more positive direction? Nutrients 2011;3:429-41.

10. Sahathevan R, Brodtmann A, Donnan GA. Dementia, stroke, and vascular risk factors; a review. Int J Stroke 2012;7:61-73.

11. De Rouvray C, Jésus P, Guerchet M, Fayemendy P, Mouanga AM, Mbelesso P, Clément J-P, Preux P-M, Desport J-C. The nutritional status of older people with and without dementia living in an urban setting in Central Africa: the EDAC study. J Nutr health Aging (in press)

12. Hall K, Hendrie H, Brittain H, Norton J. The development of a dementia screening interview in two distinct languages. Int J Methods Psychiatr Res 1993;3:1-28.

13. Grober E, Buschke H, Crystal H, Bang S, Dresner R. Screening for dementia by memory testing. Neurology 1988;38:900-3.

14. Zazzo R. Test des deux barrages. Actualités Pédagogiques et Psychologiques. Neuchâtel, Delachaux \& Niestlé 1974;7.

15. Isaacs B, Kennie AT. The Set test as an aid to the detection of dementia in old people. Br J Psychiatry J Ment Sci 1973;123:467-70.

16. American Psychiatric Association. Diagnostic and Statistical Manual of Mental Disorders 4th ed. Washington, DC: APA, 1994.
17. Petersen RC. Mild cognitive impairment as a diagnostic entity. J Intern Med 2004;256:183-94.

18. Crepin S, Houinato D, Nawana B, Avode GD, Preux P-M, Desport J-C. Link between epilepsy and malnutrition in a rural area of Benin. Epilepsia 2007;48:192633.

19. Ogunniyi A, Osuntokun BO. Determination of ages of elderly Nigerians through historical events: validation of Ajayi-Igun 1963 listing. West Afr J Med 1993;12:189-90.

20. Paraïso MN, Houinato D, Guerchet M, Aguèh V, Nubukpo P, Preux PM, Marin B. Validation of the use of historical events to estimate the age of subjects aged 65 years and over in Cotonou (Benin). Neuroepidemiology 2010;35:12-6.

21. World Health Organization. Physical status: the use and interpretation of anthropometry. Report of a WHO Expert Committee. Technical Report Series No. 854. World Health Organization; 1984.

22. O’Brien E, Asmar R, Beilin L, Imai Y, Mallion JM, Mancia G, Mengden T, Myers M, Padfield P, Palatini P et al. European Society of Hypertension recommendations for conventional, ambulatory and home blood pressure measurement. J Hypertens 2003;21:821-48.

23. World Health Organization. Global recommendations on physical activity for health 2010.

24. Copeland JR, Dewey ME, Griffiths-Jones HM. A computerized psychiatric diagnostic system and case nomenclature for elderly subjects: GMS and AGECAT Psychol Med 1986;16:89-99.

25. Hyler S. Personality Questionnaire (PDQ-4 +). New York: New York State Psychiatric Institute; 1994.

26. Morris MC, Evans DA, Bienias JL, Tangney CC, Wilson RS. Dietary fat intake and 6-year cognitive change in an older biracial community population. Neurology 2004;62:1573-9.

27. Morris MC, Evans DA, Bienias JL, Tangney CC, Bennett DA, Aggarwal N, Schneider J, Wilson RS. Dietary fats and the risk of incident Alzheimer disease. Arch Neurol 2003;60:194-200.

28. Solfrizzi V, Colacicco AM, D'Introno A, Capurso C, Torres F, Rizzo C, Capurso A, Panza F. Dietary intake of unsaturated fatty acids and age-related cognitive decline: a 8.5-year follow-up of the Italian Longitudinal Study on Aging. Neurobiol Aging 2006;27:1694-704.

29. Naqvi AZ, Harty B, Mukamal KJ, Stoddard AM, Vitolins M, Dunn JE. Monounsaturated, trans, and saturated Fatty acids and cognitive decline in women. J Am Geriatr Soc 2011;59:837-43.

30. U.S. Department of Agriculture, Agricultural Research Service. USDA National Nutrient Database for Standard Reference, Release 26. [Internet]. Nutrient Data Laboratory Home Page; 2013 [cited 2014 Mar 17]. Available from: http://www.ars. usda.gov/ba/bhnrc/ndl

31. Younis YM, Ghirmay S, al-Shihry SS. African Cucurbita pepo L.: properties of seed and variability in fatty acid composition of seed oil. Phytochemistry 2000;54:71-5.

32. Prince M, Albanese E, Guerchet M, Prina M. Nutrition and Dementia. London: Alzheimer's Disease International; 2014.

33. Hughes TF, Andel R, Small BJ, Borenstein AR, Mortimer JA, Wolk A, Johansson B, Fratiglioni L, Pedersen NL, Gatz M. Midlife fruit and vegetable consumption and risk of dementia in later life in Swedish twins. Am J Geriatr Psychiatry 2010;18:41320 .

34. Kang JH, Ascherio A, Grodstein F. Fruit and vegetable consumption and cognitive decline in aging women. Ann Neurol 2005;57:713-20.

35. Morris MC, Evans DA, Tangney CC, Bienias JL, Wilson RS. Associations of vegetable and fruit consumption with age-related cognitive change. Neurology 2006;67:1370-6.

36. Albanese E, Dangour AD, Uauy R, Acosta D, Guerra M, Guerra SSG, Huang Y, Jacob KS, Llibre De Rodriguez J, Noriega LH et al. Dietary fish and meat intake and dementia in Latin America, China, and India: a 10/66 Dementia Research Group population-based study. Am J Clin Nutr 2009;90:392-400.

37. Scarmeas N, Stern Y, Mayeux R, Manly JJ, Schupf N, Luchsinger JA. Mediterranean diet and mild cognitive impairment. Arch Neurol 2009;66:216-25.

38. Roberts RO, Geda YE, Cerhan JR, Knopman DS, Cha RH, Christianson TJH, Pankratz VS, Ivnik RJ, Boeve BF, O'Connor HM, et al. Vegetables, unsaturated fats, moderate alcohol intake, and mild cognitive impairment. Dement Geriatr Cogn Disord 2010;29:413-23

39. Panza F, Frisardi V, Seripa D, Logroscino G, Santamato A, Imbimbo BP, Scafato E, Pilotto A, Solfrizzi V. Alcohol consumption in mild cognitive impairment and dementia: harmful or neuroprotective? Int J Geriatr Psychiatry 2012;27:1218-1238.

40. Anstey KJ, Mack HA, Cherbuin N. Alcohol consumption as a risk factor for dementia and cognitive decline: meta-analysis of prospective studies. Am J Geriatr Psychiatry 2009;17:542-55.

41. Lobo E, Dufouil C, Marcos G, Quetglas B, Saz P, Guallar E, Lobo A. Is there an association between low-to-moderate alcohol consumption and risk of cognitive decline? Am J Epidemiol 2010;172:708-16.

42. Dufouil C, Tzourio C, Brayne C, Berr C, Amouyel P, Alpérovitch A. Influence of apolipoprotein $\mathrm{E}$ genotype on the risk of cognitive deterioration in moderate drinkers and smokers. Epidemiol Camb Mass 2000;11:280-4. 